\title{
An analysis of well-being in urban Nigeria
}

\section{Key words:}

Nigeria, urban, well-being

\begin{abstract}
Improving well-being of Nigerians is the aim of Nigeria Vision 20:2020, the key development policy document in Nigeria. However, as well-being is an emerging and contested concept, this paper explores how the well-being of urban citizens is understood in Nigeria, and identifies key trends affecting urban well-being as expressed by a selection of strategic elite stakeholders in Nigerian society. These included senior civil servants and politicians, various senior members of civil society groups and academia. The analysis also reveals characteristics underpinning policies for urban wellbeing.
\end{abstract}

\author{
Author \\ Dr Andrea Rigon, The Bartlett Development Planning Unit, University College London \\ Email: andrea.rigon@ucl.ac.uk Twitter: @rigonandre
}

Andrea Rigon is a lecturer at the Development Planning Unit of University College London. His work analyses how social and political conflicts among different actors shape the implementation of development interventions, particularly in informal settlements.

\section{Acknowledgments}

This research is part of the Urbanisation Research Nigeria (URN) initiative, a four year (2013-17) DFID-funded urban research program being implemented by a consortium of Nigerian and UK universities and consultancies. This paper is drawn from scoping research Rigon et al. 2015 Wellbeing and citizenship in urban Nigeria. For more information on the URN program and its reports, see the website http://urn.icfwebservices.com/ A special thanks to the Government of Nigeria, whose civil servants and elected officers at every tier of government have been very open in meeting with us. Many thanks to colleagues at Ahmadu Bello University, Benue State University, University of Lagos, and University of Ibadan. I would also like to thank the entire research team in Nigeria and in the UK (Steve Abah, Sylvanus Dangoji, Julian Walker, Alexandre Apsan Frediani, Olusegun Ogunleye, Laura Hirst). I am grateful to Sarah White and Michael Mattingly for their useful comments. Many thanks to both Dr Robin Bloch and Nikolaos Papachristodoulou at ICF for their continuing support and coordination.

\section{Introduction}

Well-being is increasingly recognised as the goal of development, in view of the now well-established critique of economic growth. The aim of the key development policy document in Nigeria, Nigeria Vision 20:2020, is to improve the well-being of Nigerians. However, as well-being is an emerging and contested concept, this article explores how strategic elite stakeholders understand the well-being of urban citizens in Nigeria, and articulate key issues for urban well-being. This is a very important task in the Nigerian context, which until two years ago was characterised by sustained growth rates at the same time as increasing rates of both income and subjective poverty. In 2016, Nigeria has fallen into recession for the first time in more than two decades. As plans and frameworks for the recovery are put forward, this paper can contribute to understand elite views on how to improve the well-being of urban Nigerians.

The article aims at presenting and analysing the dominant discourses and views amongst key influential actors. While the paper recognises that there is a diversity of perspectives, it prioritises the identification of key discourses and predominant views on key issues rather than an analysis of the diversity of perspectives within the elite stakeholders interviewed. The purpose is to provide a baseline of how those placed in a privileged position to influence policies conceptualise well-being, understand processes affecting well-being in cities, and articulate planned interventions needed to achieve well-being. 
At a broad level, according to the Millennium Development Goals (MDGs) progress report, on almost all measures poverty is more prevalent, deeper and severe in rural than in urban areas (Federal Republic of Nigeria 2013,11). However, at the same time, the incidence of urban poverty is recorded to be rising, from $35.4 \%$ in 2001 to $61.8 \%$ in 2010 (Anyanwu 2012, 9). Whilst some reports look at the size and incomes of the Nigerian middle class, the majority of whom reside in cities, to determine that a great number of Nigerians have made the jump from poor to middle class, others contend that rising incomes do not reflect the lived experience of urban residents and that in fact the middle class has experienced increased poverty or is at risk of falling into poverty.

Unemployment rates in some key urban centres are as high as 50\%, although this figure may not take into account rates of informal employment, which are high; in Lagos up to $70 \%$ work in the informal sector (Agunwamba et al. 2009, 41) and the majority of residents live at the subsistence level only. The high cost of living in many Nigerian cities is reflected by data showing that $62.6 \%$ of urban household consumption expenditure is spent on food (Federal Republic of Nigeria 2010, 56). In addition, in 2006 the incidence of absolute poverty whereby households were experiencing difficulties in satisfying their food needs was just as serious in urban as in rural areas (Potts 2012, 1389). Several articles also point to the economic and social disenfranchisement produced by unemployment and the inability to satisfy basic needs of urban life as reasons that people turn to crime and violence.

Housing is another key requirement in the promotion of well-being, but access to affordable, quality housing is a huge problem confronting the urban poor in Nigerian cities. In Lagos, up to $50 \%$ of the population lives in informal settlements (Ademiyuli and Solanke 2008, in Agunwamba 2009, 42) across some 200 different informal settlements across the city. Nationally, UN-HABITAT estimates that $70 \%$ of urban populations live in informal settlements (UN-HABITAT, in Federal Republic of Nigeria 2013, 52).

This introductory snapshot of a number of urban well-being indicators provides basic contextual information to what follows. It is important to note however, that whilst there are noticeable differences between rural and urban contexts, there exist equally important regional inequalities that impact on well-being, due to factors such as sub-national financial autonomy, differences in size, population, socio-economic conditions and resources, giving rise to variations in poverty and vulnerability between cities located in different states.

The exploratory research presented in this paper is based on semi-structured interviews with key elite actors in various sectors and cities. The next section presents the framework and the methodology for the research. The findings and analysis are divided into three main sections. The first outlines the processes, relationships and trends in urban well-being emerging from the analysis of key stakeholder interviews and secondary literature. The second explores different conceptualisations of well-being in Nigeria, as expressed by the categories of stakeholder interviewed. The third analyses the characteristics of government policies and interventions to improve well-being and briefly mentions citizens collective practices.

\section{Understanding well-being}

In recent years, a number of efforts at developing frameworks for measuring social progress have centred around the notion of well-being, which is increasingly recognised as the goal of development. Two notable examples are the 2008 Commission on the Measurement of Economic Performance and Social Progress, also referred to as the Stiglitz-Sen-Fitoussi Commission, and the OECD work on measuring well-being and progress which included a joint declaration in 2007 of OECD, UN, UNDP, European Commission and World bank committing "to measuring measuring and fostering the progress of societies in all dimensions, with the ultimate goal of improving policy making, democracy and citizens' wellbeing.

Governments have explored well-being frameworks to guide policy making and measure social progress. National development plans often indicate well-being as the central objective. However, there is not always clarity on this contested concept. Defining well-being is especially challenging because of the different ways in which the concept is understood in different contexts - and by 
different people. Within academia, well-being is an inter-disciplinary concept that is used by scholars from across the social and life sciences, and humanities. Different communities of scholars have different takes on what well-being is and use different languages to analyse it. What various authors agree on is the multidimensional character of well-being and the fact that different dimensions are deeply intertwined. This diversity in both policy and scholar communities has led to a number of wellbeing models and frameworks.

In their review of research on well-being and application to policy making, Dolan et al. (2006) identify five main approaches to defining well-being, which are underpinned by different philosophies and values, and argue that each approach has different implications for policy. This basic categorisation has been later reworked by NEF (2011) and Spence et al. (2011). In short, these are:

Objective lists: it involves defining a list of needs or conditions essential attributes for well-being, often in a hierarchical manner similarly to basic needs approaches.

Preference satisfaction: it is a purely liberal economics approach which assumes that people make rational choices in the use of their resources to satisfy their desires. Thus, income is a proxy for wellbeing and higher income corresponds to higher well-being

Hedonic accounts: this approach sees well-being as the difference between pleasure and pain Evaluative account: this approach is based on people's assessment of how well their life is going. Well-being is assessed by the individual themselves rather than by objective measurement.

Capabilites and functioning: Well-being is to be understood in terms of people's capabilities, that is the real opportunities to be and do what they have reason to value. This widely influential approach is based on Sen's capability approach and informed the human development approach in development policy.

Most wellbeing frameworks share a number of characteristics:

(1) the idea that well-being is multi-dimensional and thus the need to identify the dimensions, and their relative importance. A key difference between approaches is often linked to the centrality of a material dimension vis-à-vis other aspects of well-being.

(2) whether to focus on subjective or objective wellbeing (or a combination);

(3) the need to understand the interaction between different dimensions;

(4) the choice of the unit of analysis and understanding well-being as individual or collective, e.g. personal well-being/national well-being.

The paper is based on the assumption that different stakeholders build their understandings of wellbeing drawing upon different discourses, and that these understandings are deployed to make sense of the urban context, and of the processes, relationships and trends that affect well-being. On the basis of these understandings, different stakeholders articulate the different planned interventions needed to achieve well-being (i.e. a broad range of intentional actions to achieve well-being, including changes in the legal framework, policies, and development programmes).

Therefore, grasping dominant conceptualisations of well-being contributes to shed light on underpinning ideologies and values that inform policy interventions. Therefore, rather than providing a definition of well-being or selecting a specific approach, this paper attempts to synthesise the prevalent conceptualisations of well-being of elite actors in a position to influence policy. The analysis privileges the synthesis and presentation of stakeholders' perspectives rather than a critical analysis of dominant conceptualisations in light of a specific well-being approach. However, the paper draws some conclusions on how some of the ways in which well-being is conceptualised are then used to justify or inform policies which adversely affect the well-being of specific groups.

\section{Methodology}

A list of key stakeholder types in Nigerian cities was prepared and individuals were identified. A total of 45 semi-structured interviews were conducted. This research collected the views of policy-makers as well as policy implementers, i.e. civil servants at different tiers of government. Many participants occupied senior positions within their organisations (e.g. permanent secretary, executive director, director, chairman, traditional king), chosen because their views were more likely to have an impact on national discourses and policies. Research participants comprised 36 males and 9 females, reflecting the gender imbalance at the top of selected organisations. Some 21 participants were 
working in Government; 6 for Local Government; 8 for State Government; and 7 for Federal Government. ${ }^{1}$ Of these 6 were politicians either elected (e.g. members of state assemblies, LG chair) or appointed (e.g. state commissioners) and 15 civil servants. These were complemented by the views of a range of 19 civil society members, including religious leaders, leaders of ethnic groups, members of community organisations, members of professional organisations, and NGO staff. Finally, 5 participants were from research institutions. Thirteen participants were based in Abuja, 23 in Lagos, 3 in Zaria, 3 in Kaduna, 2 in Ibadan and one in Makurdi.

\section{Processes, relationships and trends in urban well-being}

The aim of this section is to present a picture of what key stakeholders consider to be the factors affecting well-being in Nigerian cities. Of great interest are findings that do not relate to single factors but to how key stakeholders understand the intersection of multiple factors and their relationships, and how these affect urban well-being.

Three broad trends emerged during discussions about the capacity of the Nigerian state to substantively deliver the well-being priorities of citizens, as well as in terms of the ability of Nigerian citizens to make claims. These relate to rapidly changing demographic and development realities; governance issues; and stratified systems of citizenship structured, in particular, around indigeneity.

\section{Reality outpacing planning: rapid demographic change}

A major commonality that emerged across the majority of stakeholders interviewed, particularly civil servants at state and federal levels, is that the speed of urbanisation is outpacing the capacity of government authorities to plan adequately. The rate of urban population growth is such that infrastructure and services development is left lagging and as a result, it is becoming more and more difficult for the government to keep up with the needs of the urban population.

Urban planning in a broad sense is considered critical to ensure well-being in cities. Its perceived failure in Nigeria was therefore seen as a major factor affecting urban well-being. Some civil service professionals expressed frustration with constantly tackling emergencies rather than working with a consistent long-term plan to address their causes. Whilst some planning was perceived as unrealistic in the first place, other, more realistic plans were felt to be disrupted by political interference. Other related factors regard the difficulties of government actors to view urbanisation as a positive phenomenon and their emphasis on the need to halt rural-urban migration. Another discourse shared by both civil society members and civil servants concerned the difficulty of implementing existing policies for well-being due to a lack of a system of independent monitoring implementation, the funding process, and corrupt practices.

\section{Governance}

Issues related to poor governance were seen as the main factor affecting urban well-being in Nigerian cities. This section explores particular issues related to governance as identified by key stakeholders.

Power distribution across levels of government: Political leaders and civil servants working across the three tiers of government felt that one process seriously affecting their capacity to contribute to citizens' well-being is the inappropriate level of government exercising authority on specific issues. This was attributed to different processes. Most responsibilities and powers of each level of government are set out in the 1999 Nigerian constitution, and whilst some responsibilities appear justified in terms of maintaining national unity in a complex country, others appear to fulfil the interests of the existing political national elite (Helly 2012). In other cases, through institutional practices some levels of government have appropriated powers and responsibilities officially belonging to another level of government (NBS 2012a). The issue is not only vertical (between Local Government, State Government, Federal Government) but also horizontal, for instance between departments in different ministries.

\footnotetext{
${ }^{1}$ Nigeria is a federal republic made up of 36 states. Each state is divided in a number of Local Government Areas (LGAs), currently 774 in Nigeria.
} 
In the Nigerian context, relationships between government actors are characterised by competition over power and resources, making coordination difficult. This was an issue that was clearly highlighted by civil servants. These conflicts, particularly between state governments and the federal government, often intersect with party politics, and are exacerbated where federal and state governments are controlled by competing parties.

Several examples were given which clarify the connection to well-being between the governance issues arising from federal and state conflict of interests. In Nigeria, main roads come under the control of the Federal Government, which includes a number of important corridors within the city of Lagos. Civil servants gave the example of a five year delay in the implementation of a major public transport infrastructure project which required the use of a federal road, due to complex political negotiations between the Government of Lagos and the Federal Government (which are controlled by different political parties). As public transport is a critical sector for urban well-being, such delays have had a major impact.

Another major example highlighted was the lack of state police. Politicians at all levels emphasised the need for a state police force. Responsibility for the police lies with the federal government and states are prohibited from creating their own forces. Governors therefore do not have autonomy to develop a strategy to fully tackle the issue of security at the state level.

Similar issues are experienced in terms of control over electricity. The electricity sector is regulated by the Federal Government. Whilst states are not allowed to produce and sell electricity to private users, they can produce it for the government's own use. This has led to Lagos government achieving a more stable supply for their public buildings, including hospitals, and public lighting positively affecting government productivity, health services, and security - all important factors for urban well-being.

One issue that interviewees felt to be connected in multiple ways to well-being is the concentration of power in the hands of State Governors, and their relationships with Local Government Areas. LGAs receive a federal funding allocation, however, the state government often exercises power over the management of these finances, effectively capturing this allocation and resulting in a relationship of patronage. This seriously compromises the financial and political autonomy of LGAs, and their capacity to plan and respond to the specific needs of their citizens.

Lack of city-level governance: In relation to the ability of urban citizens to actively pursue claims for their well-being priorities, a critical issue is that Nigeria lacks city-level governance. No city has a democratically elected city-level government. To some extent, the only exception is the city-state of Lagos as the city has expanded to cover most of the territory of the state, effectively rendering the Governor of Lagos State an elected mayor of the mega-city. Another exception is Abuja and its Federal Capital Territory Administration, which does provide some city level governance, but is effectively a ministry of the federal government rather than a body that democratically represents the capital's residents.

For all other cities, the number of uncoordinated local government bodies makes consistent city-level planning difficult, particularly in cities which are not state capitals. For example, the city of lbadan is spread out over five LGAs, Kaduna over four (although two also cover areas outside the city) and Zaria two. As mentioned previously, these bodies often have limited power and report directly to state governors without an intermediary authority at city level.

This lack of unified governance can increase divisions in cities. For example, in Kaduna the administrative separation of the city - which reflects the religious divide - can make it more difficult to overcome sectarian conflicts between Christian and Muslims. Different LGAs may also be run by different parties making coordination even more difficult. Moreover, the areas covered by local governments also include some rural or peri-urban areas, meaning that local government departments must plan rural as well as urban interventions. Small towns generally occupy the area of just one LGA; however, LGAs are still weak and lack autonomy from state government. 
Democracy: There was unanimous agreement on the importance of 15 years of uninterrupted democracy and associated political stability as a precondition for enhanced well-being in cities. However, it was also recognised that Nigeria's is still a democracy in transition. It is a country in which citizens still fear challenging authority to claim basic rights and therefore in which a truly inclusive democracy has not yet been achieved.

A widely shared perspective was that there are areas in which the government is still unable to perform its function as a regulator (and enforcer of such regulations) of private sector activities in a way that benefits the public and creates conducive competition. This was attributed to a lack of an adequate legal framework but also as the result of entrenched institutional practices protecting specific private sector interests.

\section{Stratified citizenship}

Another set of processes affecting well-being relate to how citizenship rights are unequally granted. Two specific processes were identified: (i) As a basis for citizenship rights, indigeneity linked to the state of origin of a citizen (or their parents) is often more important than belonging to the Nigerian state; and (ii) socio-spatial inequalities affecting the distribution of well-being and ill-being.

Indigeneity: Being an indigene or not provides differential access to services and rights. Respondents mentioned several times that being in another Nigerian state can be worse than being abroad in this respect. Whilst Nigerian law and the constitution legislate against discrimination, in practice exclusion of non-indigenes varies greatly across states and socio-economic class. Despite being born in a state, people can be excluded from scholarships and other services and told to seek such requests from the LGA of their parents' origin.

This discrimination also has implications for the capacity of people to run for political office. It is important to note that indigeneity is bestowed through patrilineal descent and therefore, the children of an indigene mother may be excluded from her indigene rights.

The concerns raised by stakeholders were also presented in an extensive report on this issue by Human Rights Watch (2006). Many states refuse to employ non-indigenes in their state civil services, and most if not all states deny academic scholarships to non-indigenes. Moreover, state universities charge higher fees to non-indigenes. This is in addition to the barriers to political rights and access to services and infrastructure to these communities (Human Rights Watch 2006). Issues of indigeneity become more salient in the context of increasing insecurity.

Urban informality and inequalities: There is a general trend in the spatial inequality of distribution of well- and ill-being. In Lagos, for example, there exists immense socio-spatial inequality, with about half of its residents living in informal settlements. People living in these areas are subject to massive forced displacement and eviction without the provision of alternatives, particularly in Lagos and Abuja. Compensation and resettlement policies only cover the few who hold titles to land. These processes lead to the destruction of livelihoods. To settle in a particular location, people make physical, financial and psychological investments over a number of years. They also build livelihoods around their current living arrangements. Starting from scratch all over again due to eviction may dramatically affect their well-being, particularly for those already facing other challenges such as debt, poor health, and old age.

When discrimination on the basis of indigeneity intersects with economic/socio-spatial inequality and high levels of chronic poverty in Nigeria, these two trends become extremely harmful for the wellbeing of many urban Nigerians.

\section{Examples of impact on urban well-being in specific areas}

The three trends described above were seen as underpinning factors affecting the coordination and equitable delivery of goods and services essential for citizens' well-being. A number of key areas in which such goods and services are inadequate to ensure the majority of citizens' well-being were raised during interviews, three of which are presented as examples below. 
Electricity: All interviews emphasised the provision of reliable electricity as a fundamental priority to ensure urban well-being, directly and indirectly. The lack of a reliable power supply was highlighted as a particular problem for households and businesses. The use of private generators is very costly and thus reduces available household income for other expenditures. The use of generators is also a serious health hazard. One major impact on well-being caused by the poor electricity supply concerns its effects on employment. The poor electricity supply was also mentioned as an important factor in the closure of textile, aluminium and other industries in Kaduna. Moreover, it also affects the productivity of public institutions and government offices.

Congestion: All stakeholders identified traffic congestion as negatively affecting the well-being of urban citizens. Congestion is a constant feature of the daily life of every inhabitant in Lagos and Abuja, affecting productivity, psychological and physical health. It was also argued that traffic congestion disproportionally affects women with childcare responsibilities. Long commutes affect wellbeing through stress, tiredness, lost time and angry feelings. Urban well-being is also affected indirectly due to reduced economic productivity caused by everyday traffic congestion. This loss of productivity was emphasised by every level of stakeholder interviewed, with senior civil servants complaining that they are unable to discipline workers for arriving late and leaving early, considering the time spent travelling to work.

Security: Different types of insecurity severely undermine well-being in urban Nigeria. The effects of the insurgency were prominent in all discussions. Boko Haram was seen as part of a global phenomenon but interviewees acknowledged that Nigeria was less prepared than other countries in how to deal with this threat. The spread of the Boko Haram insurgency was specifically connected to a lack of basic needs and the failure to deliver development in those areas of the country primarily affected.

As well as being a result of underdevelopment, the insurgency was seen as impacting on future development and ultimately on the well-being of citizens. The delivery of infrastructure (e.g. roadbuilding) in particular is impeded by the presence of the insurgency. It was also argued that such insecurity is hindering investment in the affected areas. The withdrawal of investment from the north was a cause for concern and, in the long-term, could exacerbate the North-South divide in terms of development.

The insurgency was also seen as causing two types of migration. The first flow concerns indigene people leaving the epicentre of the insurgency to escape Boko Haram and state violence. The second flow includes non-indigene traders and other business people residing in the north of the country, who no longer feel safe and can relocate their activities to their state of origin or elsewhere.

The insurgency has inevitably had a deep impact on people's psychological well-being and in certain cities this has led to changes in behaviour. Insecurity is also held to have accelerated the construction of gated communities. Whilst this trend had already started before the last wave of insurgency, processes of 'privatisation of security' have found a new legitimacy. The creation of vigilante groups is another trend. Such groups are also used to support political candidates and enforce extra-judicial justice.

An important point raised was how police and army brutality increases insecurity. State security institutions often violate the rights of people and citizens feel they cannot trust any institutions. Finally, it was argued that the prominence of the issue of security in the public discourse is used to conceal other concerns and prevent the voicing of strong criticisms on other issues important to well-being such as budget monitoring on health and education.

\section{Stakeholders' understandings of well-being}

This section analyses how the elite stakeholders interviewed conceptualise well-being. This analysis contributes to understanding how stakeholders interpret the factors that undermine urban well-being outlined in the previous sections and prepares for the analysis of policies and interventions that are in place - as well as people's practices to achieve well-being. 
Four dominant ideas of well-being emerged from the analysis.

\section{Well-being as basic needs}

The prevailing conceptualisation amongst stakeholders is that well-being is defined as the fulfilment of a set of basic needs. Employment (including self-employment) is seen as key to generating the income needed to meet such basic needs. The main strategy here is to pursue economic growth and the creation of jobs primarily through the development of the private sector.

Stakeholders emphasised three key interrelated basic needs to achieve urban well-being: food, transport, and housing. Employment was also considered by some as a basic need needed to fulfil the others. Framing well-being in terms of a set of basic needs was also thought to be useful in terms of the subjective nature of preferences and aspirations. Civil servants felt this subjectivity to be problematic for government planning, arguing that with a growing income the aspirations and scales of preference of individuals may expand and change. Moreover, well-being is "ambiguous" because "each person has their own priorities". Government policy and planning cannot therefore keep up with people's expanding preferences and therefore should focus on a standard set of basic needs, achievable for all.

\section{Well-being as a means to achieve productivity and growth}

Responses around the perceived importance of well-being for urban citizens were often connected to the productivity and thus economic growth and development of Nigeria with little or no mention of well-being in terms of rights. Another example was the view taken by some stakeholders that interventions to improve citizen health were a way to maintain citizen productivity. From a civil service perspective, maintaining productivity through well-being was also important for taxation.

\section{Well-being as security}

An alternative but consistent conceptualisation of well-being presented by stakeholders was wellbeing as security. In this instance, security was understood as a holistic term encompassing several processes. For instance, a participant from a research institution indicated that well-being for urban citizens "would be in terms of security within the city [...] security from crime, security from disasters both natural and made disasters. Good living will also be in terms of food security, the economic wellbeing and secure livelihood". This conceptualisation was very important in relation to the point often made that insecurity and uncertainty are a constant condition of urban life in Nigeria that undermines well-being, particularly psychological well-being.

While different dimensions of insecurity and uncertainty were mentioned, the issue of physical security linked to crime, violence and particularly the insurgency (including the many terrorist attacks on civilians) figured prominently in this conceptualisation. The impacts on everyday behaviour were emphasised. In areas that had been affected by intercommunal violence based on religion, security framed as peace was considered the precondition to enjoy any other dimension of well-being.

\section{Well-being as social order}

The idea of well-being as social order was prevalent amongst civil servants at State and Federal levels. The argument put forward is that well-being is the product of following policies, masterplans, and planning standards. It is when plans are not followed (e.g. due to political interference or due to incapacity to cope with rates of urban growth), that 'disorder' and 'chaos' lead to poor well-being of urban residents. For this reason, well-being was thought to be easily achievable as long as there was the political will to 'stick to the masterplan'. Following the same reasoning, a strong association was made between disorder and informality, explicitly emphasising the importance of converting the informal into the formal. This discourse around social order also often encompassed a particularly aesthetic view of well-being, to be achieved through the orderly implementation of plans and strongly associated with beautification and greening interventions.

\section{Characteristics of government policies and interventions to improve well-being}


Stakeholders' views on policies for urban well-being are strongly linked to their understanding of the relevant urban processes and their conceptualisations of well-being. The analysis of their views on policies identified four key characteristics: (1) a focus on social order; (2) the prominence of middle class concerns and exclusion of poor and non-indigenes; (3) the view of the government as enabler of (economic) development; (4) a negative view of urbanisation and need to decongest cities.

Restoring 'social order': A view shared amongst government stakeholders was that policies and planning for 'social order' are required in order to achieve well-being. This view presents a strong modernist discourse combining criteria based on aesthetics and 'order.' Planning was viewed in terms of restoring a social order lost during the rapid growth of cities. These ideas were entrenched within high levels of the civil service, amongst those holding political positions as well as planning professionals. One suggested method of achieving social order was to follow the existing masterplan and planning and building regulations. This technocratic discourse emphasises that planning is an exclusively technical and neutral process that professionals have to do for people, rather than with people.

With increased security concerns in Nigeria, discourses of social order and public order were seen as interrelated priorities. The understanding that the primary responsibility of government is to provide for the security of property and human life, and the centrality of security for enabling foreign and national investment contributed to translate security concerns into various policies.

The views on policies and planning for social order can translate into specific interventions requiring the formalisation of informal practices and processes including the explicit elimination or renewal of slums, which are considered a source of insecurity. These views chime with the reality of a number of mass evictions, demolitions and street clearances currently taking place in Nigerian cities without consideration for the lives and livelihoods of residents.

The prominence of the idea of 'social order' and the resulting attitudes towards informal settlements have led to a certain legitimisation of government actions to relocate people living in informal areas without engagement, in contrast to other countries where civil society organisations play an important role in negotiations around relocation. Research participants from civil society pointed out how largescale evictions have particularly affected the livelihoods of thousands of dwellers. A strong critical argument was made that urban policies are not only designed for the wealthy but that they directly destroy the livelihoods of the urban poor.

Who are policies for?: Another characteristic of policy linked to this idea of social order relates to who the targets of such policies are. A point that emerged from the multiple discussions is that policy interventions for well-being in cities are not focused on the needs and aspirations of the poor. Strong criticisms of current planning practices and policies were raised by some researchers and NGO members.

Some pro-poor interventions are proposed not because of their potential to improve the lives of the poor, but rather because they are cost-effective. It was argued that some interventions which could improve the well-being of the urban poor could have economic returns, for example it would be cheaper to treat dirty water rather than any subsequent water-related diseases.

A key process affecting the well-being of urban Nigerian is the exclusion of non-indigenes from accessing some public services and from running for elective offices. This process is translated into different discourses about citizenship by different actors. A recent study (Alemika, Cheeseman, and LeBas 2012) suggested that the attitudes of urban citizens towards the exclusion of non-indigenes differ. While most urban citizens think that discrimination in terms of access to services is not justified and everyone should be entitled to equal state services, the large majority are in favour of the exclusion of non-indigenes from elective offices. However, there are differences depending on the city. 
As objects of policy people in urban Nigeria are not treated equally. The views expressed by very many of the interviewees suggest that often people living in poverty are not seen as policy targets and this policy approach was rarely contested. On the other hand, there are a number of policies and practices which exclude non-indigenes but these seem to be increasingly challenged.

Government as a provider of enabling environment and infrastructure and services: Consistent with the conceptualisation of well-being presented so far, a third characteristic of policy is built around the view that government responsibility lies in providing the enabling environment for private activities that ultimately lead to well-being. According to stakeholders, government is not in the position to directly employ or provide basic needs for every citizen. However, government should create the enabling environment for people to achieve their well-being.

An important component of this environment is the provision of certain public goods, particularly infrastructure and services, that individuals, no matter how rich, cannot provide for themselves. Most stakeholders recognised that much infrastructure requires government provision or at least government regulation, and that no single actor can effectively provide certain types of infrastructure. These included good road networks, electricity, water supply, and public transportation.

Infrastructure was also closely linked to policies for well-being due to the close relationship made between well-being and productivity and the view that infrastructure is necessary for productivity. Another component of the enabling environment highlighted is the importance of facilitating the development of the manufacturing sector by harmonising taxation between tiers of government.

Decongesting the city: Government stakeholders emphasised the importance of policies to 'decongest' the city. A number of senior government officials insisted that it was important to develop and invest in rural areas to stop rural-urban migration, despite evidence pointing to the prominent role of natural growth in explaining population growth in cities. Underpinning this view, there is a negative perception of urbanisation and the idea that urbanisation can be controlled and stopped. The related idea is that urban well-being can be achieved with policies targeting rural areas so as to prevent further migration. A frequent proposal to decongest cities referred to the decentralisation of centres of activities through the creation of polycentric cities to avoid high levels of daily commuting to the city centre.

\section{Citizens practices}

It is important to mention that because the function of the state as enabler of well-being in urban Nigeria is poorly performed, citizens pursue the achievement of well-being through a number of collective practices. When public provision does fail, services (such as electricity, security, road repairs, financial services) are either obtained privately, or through a number of different collective action processes. According to stakeholders, urban citizens feel that the provision of certain public goods would be better provided by (e.g. security), or at least regulated by (e.g. electricity) the state but are obliged to seek them elsewhere.

Citizens associate and organise collective action at various scales through community development associations a collective form of organisation operating at the community level to address local problems; savings groups; ethnic-based collective action; and religious organisations.

\section{Conclusions}

The paper identified three major processes affecting well-being: rapid demographic change that makes it difficult for government to respond with adequate planning and interventions; a number of governance issues, particularly regarding the distribution of power, lack of city-level governance, and the role of the state; and the existence of stratified citizenship levels characterised by unequal access to services and rights based on socio-spatial discrimination and indigeneity. The analysis of the processes affecting well-being and specific examples revealed elite stakeholders' awareness of how different processes intersected in affecting well-being. For instance, the relationship between growth of private transport and congestion or between the lack of development in the North East and insecurity were highlighted. 
Well-being tended to be conceptualised as the achievement of basic needs through economic growth. At the same time, well-being itself was considered a fundamental means to achieve productivity and growth. Well-being was also understood through the broad notions of security, and seen as 'social order'. These four intertwined understandings of well-being demonstrate an acknowledgement of wellbeing as multi-dimensional. However, the dimensions most consistently identified and often articulated in terms of basic needs were connected with the material dimension of well-being. These understandings are mostly linked to the objective list approach and the liberal economics preference satisfaction.

Overall, the conceptualisation of well-being and how it can be achieved that emerges from key elite Nigerian stakeholders emphasises the role of the state in providing an enabling environment for investment and market-led development. This is based on a citizenship model based on 'regimes of activation' in which economic growth (assumed to directly translate into employment) is considered sufficient for citizens to achieve well-being. This vision can be at odds with policies of other countries facing high rates of economic growth as well as a significant number of people living in poverty. The Indian government issues a ration card which provides a range of social security benefits, for example, while in Latin America a number of countries have introduced conditional cash transfers and other social security programmes.

It is important to note that the view of well-being not as a goal but as a means to achieve economic growth and productivity reveals an instrumental approach, which represents the concerns of upper middle classes. In some cases, even pro-poor policies are not considered important because they increase the well-being of the poor but because they are cost-effective and ultimately improve the overall economy.

Interestingly, viewing well-being as security and social order recognises well-being as the result of a collective process linked to clear policy interventions. However, these understandings also reflect the interests of a specific elite class and the proposed policy solutions are problematic in terms of the well-being of most urban Nigerians. In particular, the negative view and criminalisation of informality often translate in evictions or interventions which disrupt informal livelihoods adversely affecting the well-being of the urban poor. The analysis of the characteristics of policies for urban well-being articulated by the stakeholders interviewed further highlights how policies are underpinned by views of urban well-being which mostly reflects concerns of the upper middle class and political elite. Finally, the perception of urbanisation as undesirable is another obstacle to the formulation of urban policies contributing to improve the well-being of all urban Nigerians.

\section{Policy findings and implications}

This paper has identified the perspectives of elite stakeholders on main trends and key areas related to urban well-being, their conceptualisations of well-being, and a number of characteristics of policies for urban well-being. Four main policy implications emerged from the analysis:

- Considering the current trends in population growth in Nigerian cities and towns, it is important to question whether the current governance structure is effective to plan and manage city development in ways that enhances residents' well-being. In particular, it is important to think about the division of roles of each tier of government.

- This study highlighted stakeholders' confidence in the view that well-being policies should aim to create the conditions for increased economic growth which will in itself be the main driver of improved well-being. However, the extent to which current economic growth is creating employment and contributing to the well-being of most Nigerians is questionable in the context of growing levels of poverty. Data from the National Bureau of Statistics (NBS 2012b) demonstrate that both absolute and subjective measurements of poverty indicate increasing poverty. Focusing mostly on the promotion of GDP growth and investment as a strategy for well-being can be contrasted with other countries with high levels of growth as well as a significant proportion of the population living in poverty but which are complementing their growth strategies with strong social policy measures. It would be important for Nigeria to implement strong social policy measures targeting the urban poor, which build upon the existing livelihoods of the poor rather than interventions that undermine them. 
- Some of the existing policies and interventions analysed do not target all urban citizens equally. In particular, there are two processes of discrimination which must be removed to achieve the well-being of all urban citizens: socio-spatial inequalities and discrimination of non-indigenes.

- This paper has revealed how the limited availability of public goods such as safety and security, as well as infrastructure and services, may affect urban well-being even in the presence of growing income levels. This research has demonstrated that there are a number of goods, services and infrastructure which are better provided or at least regulated by government but government performance is still lacking.

\section{Bibliography}

Agunwamba, A. 2009. Nigeria: The next generation - literature review. British Council.

Alemika, E., Cheeseman, N., and LeBas, A. 2012. "Attitudes towards citizenship in Nigeria." Briefing Paper 22. Oxford: IIG.

Anyanwu, J. C. 2012. Accounting for Poverty in Africa: Illustration with Survey Data from Nigeria. Working Paper Series 149. African Development Bank..

Dolan, P., Peasgood, T., and White, M. (2006). Review of research on the influences on personal well-being and application to policy making. London: Defra.

Federal Republic of Nigeria. 2010. Nigeria Millennium Development Goals.

Federal Republic of Nigeria. 2013. Nigeria 2013 MDGs Report. Abuja.

Helly, D. 2012. "Nigeria's Stability: Constitutional Reform and Beyond." Briefing Report. Bruxelles:

Observatoire de l'Afrique.

Human Rights Watch. 2006. "They Do Not Own This Place" Government Discrimination Against

"Non-indigenes" in Nigeria (Vol. 18).

NBS. 2012a. Assessment of Good Urban Governance in Nigeria. Abuja: National Bureau of Statistics.

NBS. 2012b. The Nigeria Poverty Profile 2010 Report. Abuja: NBS, WB, DFID, UNICEF.

Potts, D., 2012. Challenging the Myths of Urban Dynamics in Sub-Saharan Africa: The Evidence from Nigeria. World Development. 40 (7), 1382-1393.

Spence, A., Powell, M. and Self A. 2011. Developing a Framework for Understanding and Measuring National Well-being. Supplementary Paper, Office for National Statistics.

New Economics Foundation. 2011. Measuring our progress: The power of well-being. London. 